Supplementary Document for the paper

\title{
Dynamic Instabilities and Mechanism of the Electrochemical Oxidation of Thiosulfate
}

\author{
Zhanhe Du, ${ }^{1}$ Qingyu Gao, ${ }^{1} *$ Jiamin Feng, ${ }^{1}$ Yongchao Lu, ${ }^{1}$ and Jichang Wang ${ }^{1,2, *}$ \\ 1. College of Chemical Engineering, China University of Mining and Technology, Xuzhou, Jiangsu \\ Province, 221008, PR China \\ 2. Department of Chemistry and Biochemistry, University of Windsor, 401 Sunset Ave., Windsor Ont., \\ Canada N9P $3 P 4$
}

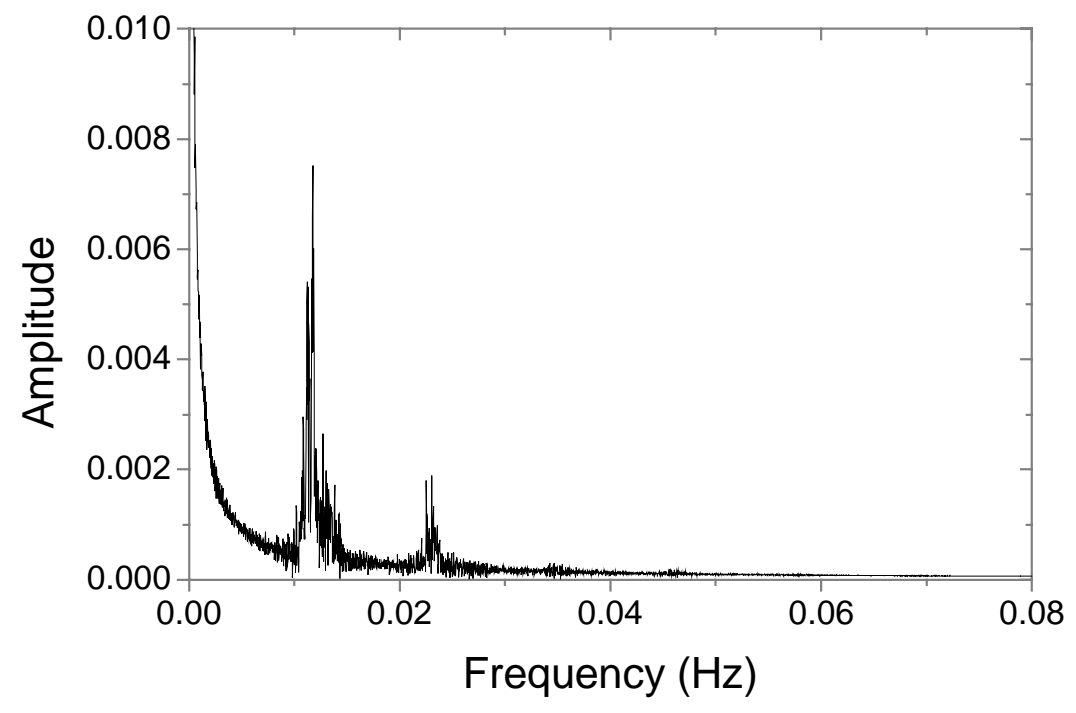

Fig. 1 Power spectrum of the time series shown in Fig. 5c.

* Corresponding authors. Tel./Fax: +86 5163995758 (Q. Gao); Tel.: +1 519253 3000x3540; Fax: +1 519973 7098. (J. Wang).

E-mail addresses: gaoqy@cumt.edu.cn (Q. Gao); jwang@uwindsor.ca (J. Wang). 

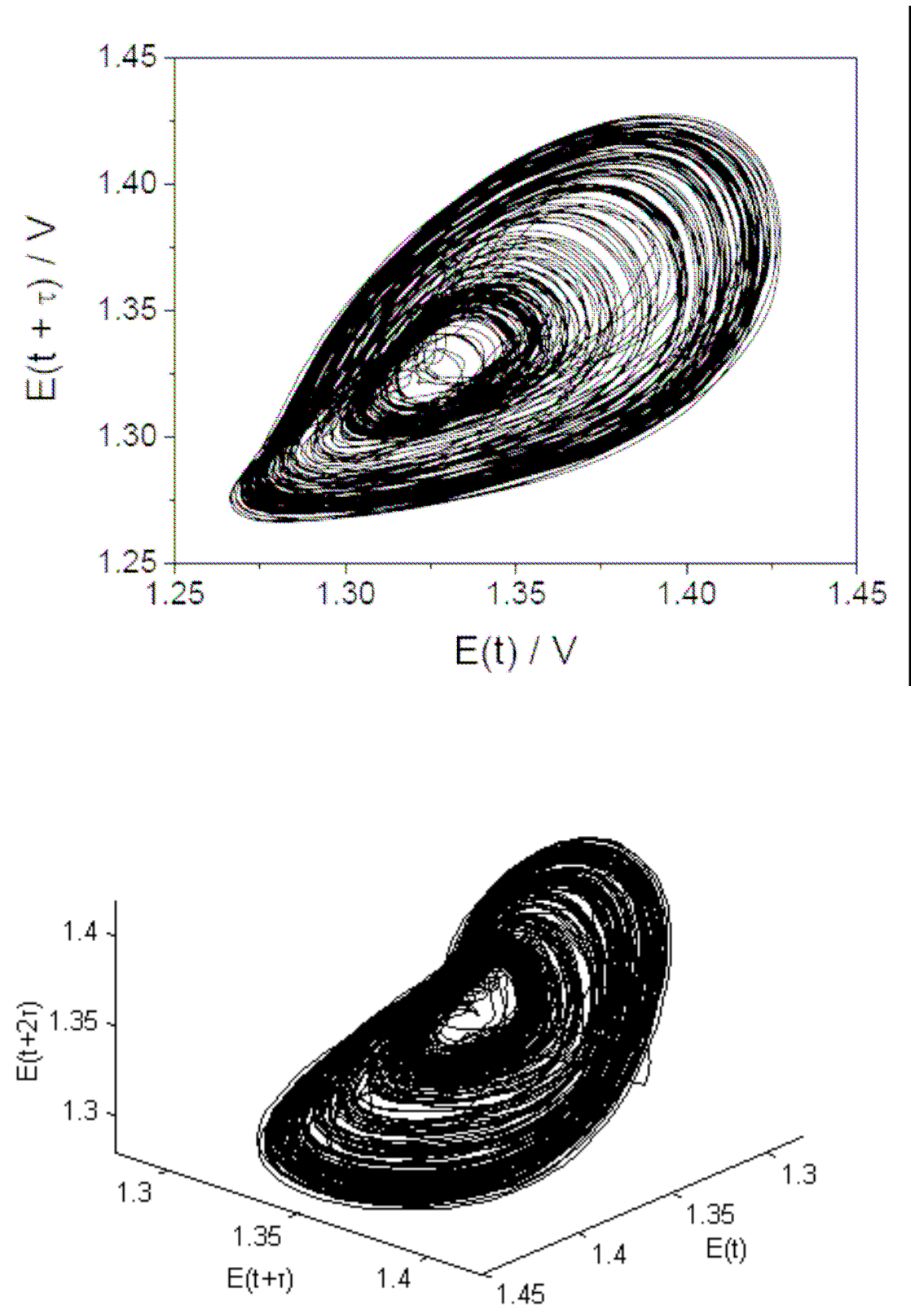

Fig. 2 Attractors obtained by delay methods, where the delay time $\tau$ equals $9.6 \mathrm{~s}$. 